\title{
IMPLEMENTATION OF RESULTS-ORIENTED DEFENSE RESOURCE MANAGEMENT IN THE BULGARIAN MOD - PROBLEMS AND WAY AHEAD
}

\author{
Dobromir TOTEV
}

\begin{abstract}
The practical implementation of results-based resource management requires realistic and clear strategies at both national and international level, correct prioritization of tasks (projects), optimal use of resources, and also development of a sense of purpose and transparency. There is also a necessity of permanent adaptation and skills for change management. The improvement of the efficiency of Defense Resource Management in the Bulgarian MoD requires some additional changes and developments, such as: (1) Complete implementation of an effective Force Management System, which will set the identification and development of the required operational capabilities (ROCs) of the Bulgarian Armed Forces, and its synchronization with the other two sub-systems - the Integrated Defense Resource Management System (IDRMS) and the Acquisition System; (2) A need for more complete and realistic vision in the Defense Programming Guidance (DPG); (3) Enhancing the role and contribution of senior leadership; (4) Introduction of an integrated MoD; (5) Adequate financial projections; (6) Preparation of suitable risk analyses; (7) Use of the Balanced Scorecard (BSc) methodology; (8) The IDRMS information and technology environment should be improved by development and support of the Defense Resource Management Model database and application of the results for modeling and systematic analysis of the programs.
\end{abstract}

Keywords: Defense resource management, force management system, Balanced scorecard, performance indicators.

Undoubtedly, the Armed Forces have to perform their tasks with the available resources. This underlines the vital importance of realistic and clear strategies, at both national and international level, for proper prioritization between tasks, correct use of resources, but also for developing a sense of purpose and transparency. There is also a need for permanent adaptation and capabilities for change management, and the issues have to be realized in a framework of structures, equipment, and budget that is not stretchy at all. 
Results-based management is a life-cycle approach to management that integrates strategy, people, resources, processes and measurements to improve decision-making, transparency and accountability. The approach focuses on achieving outcomes, implementing performance measurement, learning and changing, and reporting performance.

In the year 2000, the Bulgarian Ministry of Defense (MoD) and the Armed Forces adopted a new multi-year, program-based, financially constrained Integrated Defense Resource Management System (IDRMS), which was developed on the basic principles of the Planning, Programming, and Budgeting System (PPBS)

The purpose of the new IDRMS is to produce a multi-year plan, a multi-year program, and an annual budget for the Ministry of Defense that reflects the best mix of forces, equipment and support attainable within anticipated fiscal constraints and in accordance with the established priorities. It is a major instrument in achieving the build-up of required defense/ combat capabilities needed to support the national security strategy. The new IDRMS is compatible with the planning systems of NATO and its member states.

The implementation of this new system has resulted in the enhancement of the democratic control of the Armed Forces and the transparency of the defense budget. In addition, the new system has increased the awareness of senior leaders of the importance of the financial dimension of defense planning. The system has also facilitated the allocation of funds to individual programs, increased the level of involvement of program managers in setting financially-realistic program objectives, and made program managers more accountable for the management of the financial resources allocated to the accomplishment of those objectives.

The program structure embraces the entire activity, resources, functions and tasks of the MOD, the GS and the units and allows development of the MOD's budget on program principles.

It is clear now that the IDRMS has totally changed the decision-making environment and relationships among all kinds of planning subsystems in the MoD. This requires new system links for better integration of the existing planning processes to the resource management. Moreover, the new resource approach calls for the establishment of a new MoD management system - Force Management System (FMS). In fact, we need new planning system architecture to ensure the rationality, realization and resource effectiveness of our intentions and programs, especially those for modernization and development of the Armed Forces. It seems that modernizing the Armed Forces to accomplish changing military tasks and doing this with fewer budgetary resources will be the main driver for improvement of the defense planning process. 
To make the current practice in defense resource management really results-based management and to derive the full benefit of the implementation of the IDRMS and FMS as a whole, the following additional changes and improvements need to be accomplished by the MoD.

\section{Main Challenges}

Complete implementation of an effective Force Management System (FMS), which will set the identification and development of required operational capabilities (ROCs) of the Bulgarian Armed Forces, and its synchronization with the other two sub-systems - the Integrated Defense Resource Management System (IDRMS) and the Acquisition System. Bulgaria's defense planning process should be completed as soon as possible by implementing a comprehensive detailed Force Planning. It is essential in order to determine force requirements and to provide the basic rationale for the development of the armed forces. The existing military plans and agreements could not compensate for the lack of detailed Force Planning, especially in the military equipment modernization process. In fact, the $\mathrm{MoD}$ is unable to allocate resources consistently to our highest priorities without a detailed Force Planning. Only when we have articulated quite specifically the military tasks, we can think concretely about needed capabilities and alternative approaches to acquire them. We cannot analyze the investment plans if the capability objectives are not clear, stable and integrated. Finally, the lack of detailed Force Planning is a very serious obstacle to the transparency in the modernization goals establishment process.

Complete implementation of an effective Force Management System is vital to ensure that critical elements of defense planning are synchronized to produce a trained and ready force capable of accomplishing all assigned missions. Management of the activities to produce a trained and ready force is a complex task with many interrelated elements. The Force Management System is a system for the management of change within the Bulgarian Armed Forces. It provides the tools for effective and prioritized use of resources and a rational basis for decision-making. The system enables effective trade-offs between scarce resources to modernize and create a more efficient defense system for Bulgaria.

These systems enable the Ministry of Defense and the Bulgarian Army to manage the process of change necessary to modernize their organizations and units.

The ROC System provides the organizational commanders with a methodology and a structured system to determine the required operational capabilities derived from the national goals and objectives operating within the existing strategic and national environment, to design a future force structure with these capabilities, and to develop a plan to achieve these capabilities. 
The purpose of an integrated Acquisition System of the Ministry of Defense and the Bulgarian Army is to translate the required operational capabilities into affordable, reliable and sustainable armaments, equipment, services and infrastructure. This system includes planning, design, development, testing, contracting (procurement), production, deployment (fielding), integrated logistics support, and disposal of systems, equipment, infrastructure, materiel, or services to support military missions. The Acquisition System establishes a management structure, organizational responsibilities and procedures to acquire and sustain the needs of the Ministry of Defense and the Bulgarian Army. The objective of the Acquisition System is to affordably develop, procure and manage materiel, services and infrastructure to meet validated Mission Needs Statements.

The Acquisition System is based on a life-cycle management model that systematically manages the entire life of armaments, equipment and infrastructure from concept development to disposal. The system establishes organizational responsibilities to manage the acquisition processes that produce four products to provide operational capabilities. The Acquisition System is fully integrated and linked with the other two systems of the Force Management System and the existing legal and logistics systems. New acquisition requirements or capabilities are developed and identified by the ROC System. Resources to acquire these capabilities are allocated and managed by the Integrated Defense Resource Management System (IDRMS). The Acquisition System acquires the capabilities required by the ROC System by contractually matching technology and industry to capabilities, using the financial resources of the IDRMS.

There is still need for a more complete and realistic vision in the Defense Programming Guidance (DPG) of top-level goals and objectives of the MoD and their priorities and timing. In part, this problem may be due to the lack of a good program cost estimation model. The inability to efficiently develop alternative programs makes it difficult for the MoD and the General Staff leadership to be aware of the full range of options available and their strengths and weaknesses.

Improving the Quality of DPG. This aims to improve the quality of the planning phase of the IDRMS and hence the utility of its primary product - the DPG. Improving the quality of the goals and objectives prescribed in the DPG and their priorities and timing will require establishing of more effective linkages between the other defense planning processes that support the Bulgarian FMS (ROCs' outcomes, force structure planning, modernization planning, logistics planning, human resources planning, etc.) and the IDRMS. ${ }^{1}$

Role and Contribution of Senior Leadership. The level of involvement of senior military and civilian leadership in the resource planning process needs to be in- 
creased, particularly with regard to the development and approval of DPG, the review and approval of proposed programs, as well as the distribution of limited financial resources. The authority and responsibility of senior leadership has to be strengthened in order to achieve better integration of IDRMS. Specific area of competence should be established and direct connection between senior officials and program manager should be developed. Lack of stable directorates and frequent changes in the MoD hamper the implementation of the systems as well.

The Introduction of an Integrated $M o D$ is a hallmark of democratic civil-military relations and "the issue is directly related to civil-military relations, civilian oversight over armed forces and the efficient use of defense resources in the public interest."

The separation of the Ministry and the General Staff and the specific relations of subordination between the Minister and the Chief of the General Staff determine the lack of institutionalized horizontal connections between their structural elements, lack and negative impact on the promptness and efficiency of the decision-making process. This fact determines the extreme slowness of the bureaucratic procedures of transferring and receiving information and coordination of decision drafts. There is no clear enough delegation of certain rights to the directors in $\mathrm{MoD}$, according to their competence. The separation of the military expertise (the General Staff) from the civilian expertise (the Ministry of Defense) instigates mistrust, opposition and alienation between the personnel of the two institutions. There is a very negative practice to divide defense programs into two groups: programs related to $\mathrm{MoD}$ and programs related to GS and services and the Programming Council spends a lot of time to discuss the funding ratio of these two groups of programs. There is a duplication and partial overlap of functions among the planning directorates of the Ministry and the General Staff, as well as among the directorates in the Ministry of Defense, the directorates and the executive agencies, the directorates of the General Staff and its directly subordinated commands. The following areas of duplication exist between the "Defense Planning and Programming" Directorate of the Ministry of Defense and the "Planning of Defense and Armed Forces" Directorate of the General Staff:

- Analysis of defense resources of the country and the Bulgarian Army in midand long-term plan and preparation of a strategic frame for their distribution and use;

- Collection of information about the defense resources of the country in longand mid-term and preparation of proposal for their distribution and use;

- Advise on financial parameters for program maintenance for the next fiscal year; 
- Participation in the development, coordination, analysis and control of the execution of the defense programs in terms of goals, approaches, resources and time;

- Preparation of analyses, reports, assessments and forecasts, necessary for the proper implementation of the processes of planning, programming, budgeting and management of defense programs.

Continuing Education. There is a need for continuing education, especially in the major program offices, concerning (1) the role of supporting plans (such as Plan 2015 and the recent modernization and force management plans) in the program development and review processes and (2) the role and responsibility of program managers in developing and proposing balanced and integrated multi-year programs. There is a very important need for education of senior civilian and military leadership of the MoD and the GS about management and use of FMS and regulations of planning and programming of defense resources.

Lack of Adequate Financial Projections. A stronger relationship needs to be developed between the MoD and the Ministry of Finance (FM) in order to ensure first that more realistic and firm financial projections are available prior to the start of preparation of the Programming Guidance and second that the macro-frame is adjusted before initiating the program review phase of the resource planning cycle.

Lack of Adequate Risk Analysis. During program review, the military, political and economic risks associated with the achievement of the primary objectives assigned to each major defense program should be presented to senior management. These assessments conducted by the General Staff (military risk) and the MoD staff (political and economic risk) should identify potential situations where both the likelihood of failure and the implications of such a failure are significant. In such cases, it is important that alternative actions be identified and assessed that, if implemented, would reduce the identified risk to an acceptable level. These alternative actions may include changes of the original objectives or increase of the available funding.

\section{Applying the Balanced Scorecard}

The Application of the Balanced Scorecard (BSc) methodology ${ }^{3}$ and the developed on its basis performance metrics can improve significantly performance management of IDRMS. The BSc performance management framework helps in reporting on value added and demonstrating results to Program Managers in the Bulgarian Armed Forces.

The Balanced Scorecard methodology translates strategy into action. Working through the balanced scorecard process enables management to define those key per- 
spectives that will drive the business to success, as well as to define how to measure them. The balanced scorecard helps organizations align multiple strategies, from various units, to the organizational strategy by linking their deliverables to those key perspectives that drive the business. The Balanced scorecard provides a clear understanding of the strategy and how it is supported by the commitment to objectives from various divisions and functional units of the organization. Ongoing performance measurement and periodic evaluation are key tools through which progress is determined. Performance measurement and evaluation present valuable opportunities to learn and adjust so that the desired results may be achieved. The BSc provides reporting on results through the provision of integrated financial and non-financial information. Results-based information is used for both internal management purposes and for external accountability to Parliament and Taxpayers. The reporting phase provides also a feedback helping managers to understand what has worked fine and what has not: a process of learning and adjusting that feeds into the next planning cycle. And, finally, it is a very important fact that the BSc concept and terminology can remain constant regardless of political changes.

Table 1 presents an example of a Defense Balanced Scorecard, which is suitable for the Bulgarian MoD. ${ }^{4}$

Table 1: Exemplar Balanced Scorecard.

\begin{tabular}{|c|c|}
\hline Strategic Targets & $\begin{array}{c}\text { Performance Indicators } \\
\text { (Lagging / Lead Indicators) }\end{array}$ \\
\hline $\begin{array}{l}\text { STRATEGIC OUTCOMES (Delivering } \\
\text { what the Government expects) }\end{array}$ & \\
\hline $\begin{array}{l}\text { Operations: Conduct successfully all opera- } \\
\text { tions and other military tasks. }\end{array}$ & $\begin{array}{l}\text { 1. Ability of the Armed Forces (Army) physi- } \\
\text { cally to deploy its forces in operations }-40 \% \\
\text { 2. } 8 \% \text { of the Army, X\% of the AF and } \mathrm{Y} \% \text { of } \\
\text { the Navy to be deployed in operations or other } \\
\text { military tasks during a specified time frame } \\
\text { 3. Operational capacity of equipment }- \text { actual } \\
\text { equipment } V \text { is required to be more than ... } \\
\text { 4.... }\end{array}$ \\
\hline $\begin{array}{l}\text { Effectiveness: Deliver military capability to } \\
\text { meet Government requirements. }\end{array}$ & $\begin{array}{l}\text { 1. Ensure that more than } 70 \% \text { of units report } \\
\text { no critical or serious weaknesses against their } \\
\text { required peacetime readiness levels during a } \\
\text { specified time frame (example of Lead Indi- } \\
\text { cators) } \\
\text { 2.... }\end{array}$ \\
\hline
\end{tabular}




\begin{tabular}{|c|c|}
\hline Strategic Targets & $\begin{array}{c}\text { Performance Indicators } \\
\text { (Lagging / Lead Indicators) }\end{array}$ \\
\hline $\begin{array}{l}\text { Defense Policy: Formulate and implement } \\
\text { Defense policy. Provide defense policy that } \\
\text { matches new threats and instabilities. }\end{array}$ & $\begin{array}{l}\text { 1. How Bulgaria meets its commitments in } \\
\text { support of NATO Response Force? - level of } \\
\text { operational capability ... } \\
\text { 2. 'Usability' of military forces - meeting us- } \\
\text { ability targets of NATO } \\
\text { 3. ... }\end{array}$ \\
\hline $\begin{array}{l}\text { RESOURCE MANAGEMENT (Planning } \\
\text { and managing our resources) }\end{array}$ & \\
\hline $\begin{array}{l}\text { Annual Budget: Maximize our outputs } \\
\text { within allocated financial resources. Control } \\
\text { resource expenditure within budgeted limits. }\end{array}$ & $\begin{array}{l}\text { 1. Variation between planned and real execu- } \\
\text { tion of resources by defense programs during } \\
\text { the Budget Year to be no more than } 5 \% \\
\text { 2. Actual in-year cost growth }-3 \% \\
\text { 3. Budget predictions are met and actual ex- } \\
\text { penses vary less than } 3 \% \text { from budgeted ex- } \\
\text { penses } \\
\text { 4. Number of internal and external audit re- } \\
\text { ports to be more than ... } \\
\text { 5. Assessment of the level of transparency of } \\
\text { military budgeting } 5 \text {... } \\
6 . . .\end{array}$ \\
\hline $\begin{array}{l}\text { Manning Levels: Recruit, train, motivate, } \\
\text { and retain sufficient military personnel to } \\
\text { provide the military capability necessary to } \\
\text { meet Government's strategic objectives. }\end{array}$ & $\begin{array}{l}\text { 1. Manning Balance within each service (sur- } \\
\text { plus/deficit over the year) - between }-10 \% \\
\text { and }+1 \% \text { of the requirement } \\
\text { 2. Gains to Trained Strength (numbers of } \\
\text { trained recruits provided to the front line) - } \\
\text { more than } 80 \% \text { of Army, } 85 \% \text { of Navy, } 90 \% \\
\text { of AF } \\
\text { 3. Medically Fit for Task - at least } 90 \% \text { of } \\
\text { Service personnel to be medically fit for tasks } \\
\text { 4. Premature Voluntary Release Exits - no } \\
\text { more than } 7 \% \text { for Army, } 4 \% \text { for AF, } 4 \% \text { for } \\
\text { Navy } \\
\text { 5. Age profile of the Armed Forces to be ... } \\
\text { 6. Rank profile of the Armed Forces to be ... } \\
\text { 7. ... }\end{array}$ \\
\hline $\begin{array}{l}\text { Defense Estate: Have an estate of right size } \\
\text { and quality, effectively managed. }\end{array}$ & $\begin{array}{l}\text { 1. Identify for disposal land and buildings } \\
\text { with a value of over ... M } \\
\text { 2. Infrastructure required to fulfill Defense } \\
\text { Forces' roles V's actual infrastructure to be }\end{array}$ \\
\hline
\end{tabular}




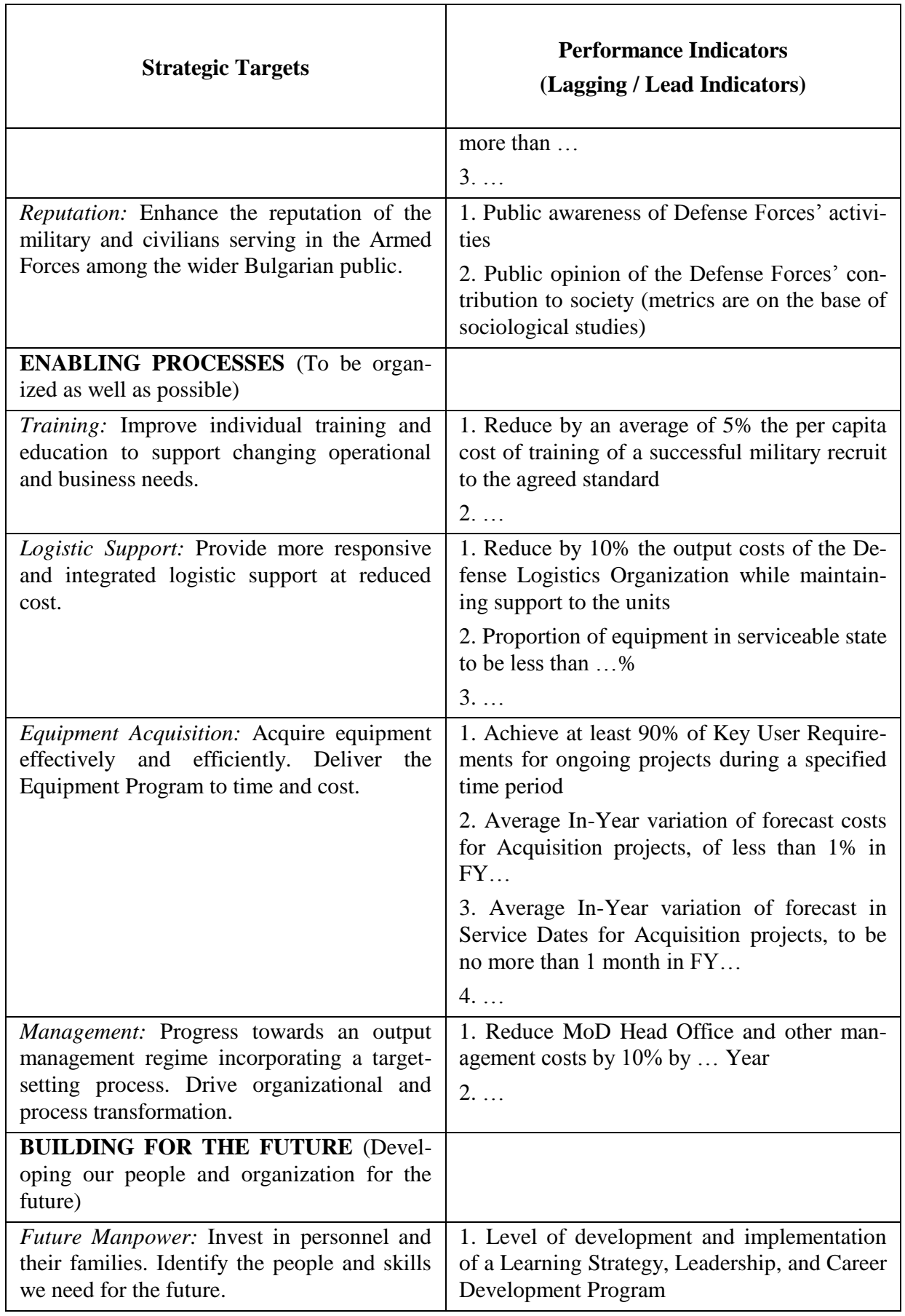




\begin{tabular}{|c|c|}
\hline Strategic Targets & $\begin{array}{c}\text { Performance Indicators } \\
\text { (Lagging / Lead Indicators) }\end{array}$ \\
\hline & $\begin{array}{l}\text { 2. Improvement in Quality of Life: number of } \\
\text { family houses, which are provided for military } \\
\text { personnel in Year } \\
\text { 3.... }\end{array}$ \\
\hline $\begin{array}{l}\text { Information: Exploit information more fully } \\
\text { as a strategic asset. }\end{array}$ & $\begin{array}{l}\text { 1. Information architecture and performance } \\
\text { infrastructure cover } X \% \text { of Units } \\
\text { 2. Level of integration of defense information } \\
\text { infrastructure to be ... } \\
\text { 3. Reported serious weaknesses in protection } \\
\text { of MoD networks and information resources } \\
\text { to be less than ... } \\
\text { 4.... }\end{array}$ \\
\hline $\begin{array}{l}\text { Technology: Ensure the continuing avail- } \\
\text { ability of sound technical advice and of ad- } \\
\text { vanced and affordable technology. }\end{array}$ & $\begin{array}{l}\text { 1. Number of R\&D studies and projects } \\
\text { 2. Number of high quality experts engaged in } \\
\text { managing defense projects } \\
\text { 3.... }\end{array}$ \\
\hline
\end{tabular}

\section{Applying the Defense Resource Management Model}

The IDRMS information and technology environment should be improved by development and support of the Defense Resource Management Model (DRMM) database and application of the results for modeling and systematic analysis of the programs. DRMM is the main instrument for analysis and modeling of the defense resources. DRMM is designed to be an analytical tool used by high-level military/civilian planners in the macro analysis of a given country's defense system. ${ }^{6}$ DRMM is a computer model based on the U.S. defense planning practices. DRMM integrates force capability and cost assessment data into a single model to compare various tradeoffs between different force structure alternatives. The model is designed so that planners can create and modify the model's fundamental characteristics of a force structure to include force structure, equipment levels, manning, peacetime training, wartime stockpiles and fiscal management practices (Figure 1).

The model produces outputs, both tabular and graphical, that quantify a country's force capability that can then be compared to alternative force structures and against the capability of a notional opposing or comparative force. Moreover, DRMM contains integrated force capability assessment and cost analysis modules that help to model the benefits of different force programs. The information provided by the model can assist defense managers in making informed decisions. ${ }^{7}$ 


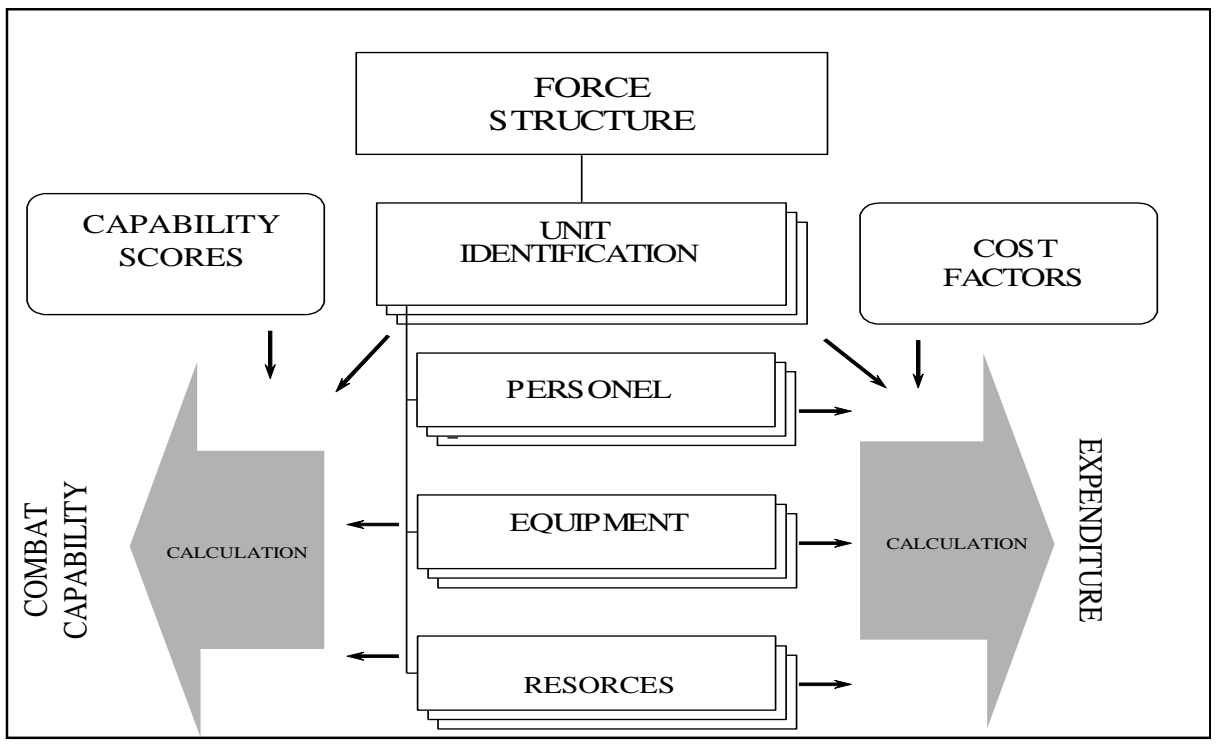

Figure 1: Elements of the Defense Resource Management Model.

The DRMM is designed to assist governments with a program that will:

- Help civilian defense and military officials develop cost-constrained, costeffective defense programs;

- Familiarize officials with U.S. Planning, Programming and Budgeting System (PPBS) techniques and methodology;

- Provide military and civilian leaders with a model to use in planning for national defense;

- Help to balance national defense expenditures against economic and political reform efforts; and

- Assist countries in providing for their defense requirements during a period of (severely) constrained budgets.

The DRMM operates on any IBM-compatible personal computer in the Windows environment. Developed using the Microsoft Visual FoxPro database management system, the DRMM stores tens of thousands of data elements representing key characteristics of any given national military force structure.

The DRMM is a data model consisting of four different types of data: force setup data, cost setup data, force (or unit) data and cost factors. Force setup data consists of qualitative information, such as the universal set of weapons types, war reserve mate- 
riel types, personnel types, and critical unit characteristics to be used in the model. Force setup data also includes limited calculation factors such as the range of possible unit mobilization times. The setup data serves as the building blocks or reference lists of information that will be used to assign characteristics to specific units or whole force structures to include the Opposing Force/Comparison Force. Matching specific unit information with force setup data creates force (or unit) data.

Cost setup data defines country-specific currencies, cost accounts, budget categories, project names, inflation factors, and unit types. The second level of data is the Cost Factors for personnel, equipment operating, unit operating, equipment procurement, and project costs. These can be defined as either "actual" cost based on historical pricing or "standard" costs from engineering or financially calculated standards. It is also at this level where funding factors can be applied to the individual cost factors. Inflation rates are also found at this level.

The model uses setup data to facilitate the user's entry of force data and cost factors. In the DRMM there will be only one combined force-cost body of setup data, which remains constant for all alternative force structures modeled. Conversely, there will be as many combined sets of force (or unit) data and cost factors for each force structure alternative entered into the model. The differences are in the multiple Force and Cost data sets, particularly in quantities for uniquely defined alternatives.

The accumulated experience in working with DRMM was used in the Bulgarian MoD in a very qualified manner during Defense Reform Studies in 1999 and Strategic Defense Review in 2003-2004. Qualitative and quantitative methods for defense and force planning were used by experts in the Ministry of Defense in the following procedure: Defining approximate personnel strength of the Armed Forces through preliminary design of a number of forces models with varying personnel strength. For this purpose, the experts designed hypothetical, but realistic, alternatives of the Armed Forces with different personnel strength at 100 percent manning under current training requirements. The current structure of Armed forces was also taken under consideration. Each alternative had different organizational structures and amount of equipment depending on the number of personnel. Expenditures and capability scores were estimated for each case. It was estimated that capability scores of the current structure of Armed forces considering the disrepair of equipment, scarce resources and real training level was equal to the capability scores of the Armed Forces with less personnel. Defense budget and expenditures were compared and the appropriate range for personnel strength was chosen. At the second stage, the experts designed alternatives of realistic horizontal and vertical organizational structures of the Armed Forces with varying ratios among services, branches, and major types of weapon systems, and varying proportions between resources for sustainment and modernization of the Armed Forces. Detailed comparative tables were calculated for each alter- 
native including personnel strength, for categories, and budget projections. The results from the studies had a critical role in the preparation of the planning guidance of the Minister of Defense for drafting "The Plan for Organizational Structure and Development of the MOD by the year 2004" and "The Plan for Organizational Development and Modernization of the MOD by the year 2015." This example for practical implementation of DRMM confirms the significant role of the analytical tools, such as DRMM, in improving the process of Defense Resource Planning and Management.

The Armed Forces are committed to deliver value-for-money defense services to the Bulgarian people. The assigned roles will be fulfilled while simultaneously ensuring that from the resources available the Armed Forces maintain the maximum capacity.

\section{Notes:}

1 Bisserka Boudinova, "Transparency in Defence Resource Management - Problems and Solutions," Information \& Security: An International Journal 11 (2003): 73-91.

2 Velizar Shalamanov, "Integrated Defense Management Model in the Context of the Strategic Defense Review," Security Focus Newsletter 1/2 (June 2003).

3 Robert S. Kaplan and David P. Norton, The Balanced Scorecard: Translating Strategy into Action (Harvard Business School Press, September 1996); Robert S. Kaplan and David P. Norton, Strategy Maps: Converting Intangible Assets into Tangible Outcomes (Harvard Business School Press, February 2004).

${ }^{4}$ For the preparation of this example, the BSc introduced for the MoD of the UK has been taken as a main source.

5 A "Methodology for Evaluation of the Budgeting Process in the SEE countries" was created within the framework of the "Budget Transparency Initiative for SEE," which may serve as a performance indicator. Todor Tagarev, "A Means of Comparing Military Budgeting Processes in South East Europe," Information \& Security: An International Journal 11 (2003): 95-135.

6 Defense Resource Management Model, User's Manual (Department of Defense, US, 1998).

7 Dobromir Totev and Bisserka Boudinova, "Information Support for Effective Resource Management," Information \& Security: An International Journal 6 (2001): 138-150.

DOBROMIR TOTEV, Colonel in the Air Force, holds a M.Sc. degree in Radar \& Automatics from the Artillery and Air Defence Academy in Shumen, Bulgaria (1980). Colonel Totev is graduate of the "G.S. Rakovsky" Command and Staff College in Sofia (1991), the Defense Resource Management Course (DRMI) in Monterey, California (1999), the NATO Defence College in Rome, Italy (2002). He holds also a M.Sc. degree in Economics of Defence and Security from the Economics University in Sofia. Colonel Totev was an active member of the team developing the Bulgarian defence resource management system and personally led a number of activities in its initial implementation. E-mail: totevd@yahoo.com. 